\title{
Cultivation of Socialist Core Values based on Foreign Language Classroom Teaching
}

\author{
Kun Yang, Yongliang Ma, Weiwei Luo \\ School of Foreign languages, Hebei University of Technology, Tianjin, 300122, China
}

Keywords: Socialist core values, Foreign language, Classroom teaching

\begin{abstract}
Socialist core values carry on the essence of Chinese traditional culture and the achievement of global civilization, which conform to the pursuit of modern people for beautiful values. Foreign language can be regarded as a direct collision of Chinese and western cultural values. We should always persist in the subjective status of learners, and make great efforts to implement socialist core values into classroom teaching. This paper states the necessity of education for socialist core values based on foreign language classroom teaching, analyzes main issues existing in cultivation of socialist core values through foreign language classroom teaching, and proposes relevant strategies for integrating cultivation of socialist core values into foreign language classroom teaching.
\end{abstract}

\section{Introduction}

Under the general trend of world economy integration and informatization in recent years, it becomes more and more frequent for economic, cultural and business exchanges between China and foreign countries. Moreover, China is in the new situation of comprehensive deepening of reform. Various values and social ideological trends become more and more complicated. In particular, so-called universal value, money worship and other ideological trends introduced from western countries disturbed the values of Chinese people, especially for young students. Young people are served as hope of a country and a nation as well as important human resources for long-term sustainable development and progress in China. It becomes very important for whether they can acknowledge and accept socialist core values. Thus, it is necessary to introduce the education of socialist core values into classroom teaching. In the process of foreign course teaching, foreign language classroom is an important site for cultural exchange and collision between China and foreign countries. Therefore, it is necessary to integrate socialist core values with Chinese characteristics into the whole process of foreign language classroom teaching, so as to realize "three-into" (into textbook, into classroom and into brain), continuously intensify internal identity of learners, and implement it consciously.

\section{The necessity of education for socialist core values based on foreign language classroom teaching}

All teaching courses contain rich thought and value connotation. Foreign language, as a course of language practice, has an extremely important status in classroom teaching. Thus, it decides that fact that it should become one of important channels for implementation of education for socialist core values. Foreign language teaching can provide training of language skills for learners. More importantly, it is also a process to understand and get familiar with a new external culture. At the same time, foreign language teaching is also a learning process of value and view of life. The education purpose of all languages is to make this nation to recognize and understand important value systems in the world. Therefore, it naturally has national character and humanity. With diversification of foreign language textbooks and richness of humanistic spirit, it is quite beneficial for cultivation of students' moral accomplishment. On this basis, we should enhance the cultivation of personality trait. The socialization process is finished for the students. However, language culture communication and cultural values are not changed since then. Compared with other professional courses, students are influenced more by views of life and values from western countries in foreign language classroom 
teaching. Naturally, the impact becomes more direct and more remarkable. To stick to socialist core values with Chinese characteristics, it seems quite urgent for integration of education for socialist core values into foreign language classroom teaching.

For foreign language teaching, western values continuously emerge in large numbers in the instruction of knowledge and skills. Difference between value and culture is revealed from deep understanding of a word to certain meaning of this word and from unspoken words of a sentence to the pattern expressed by language. Practice has proved that it is quite necessary for foreign language teachers to give instruction and guidance to learners in terms of understanding of socialist core values. At the same time, it is also extremely effective. In foreign language teaching, various conflict always appear between Chinese and western cultural values. It is just the best way used to reasonably combine language teaching with culture teaching. On the basis of foreign language teaching, therefore, we should also make an in-depth analysis on relevant reasons for difference between Chinese and western cultural values, realize trans-cultural understanding between the two kinds of value, and instruct such understanding to learners. Thus, learners can be made to avoid one-sided instructions on the level of cultural value while facing new cultural collisions. At this time, foreign language teachers should create good foreign language classroom atmosphere as much as possible, and really move language teaching onto the "stage". In foreign language classroom, teachers and students play different roles according to different teaching contents. Thus, culture in teaching content is implemented in mutual exchange and learning.

\section{Main issues existing in cultivation of socialist core values through foreign language classroom teaching}

The first one is it is relatively laggard for the research on education for socialist core values in foreign language classroom teaching. In foreign language education, western developed countries will always combine education of values in this country, i.e. combination with all-subject teaching, combination with all-personality education and combination with self-assessment. However, it is still in blank for the research on education for socialist core values in foreign language classroom teaching in China.

The second one is that young students have certain problems in values at present. A survey is made with foreign language classroom teaching as an example. It can be found that values of Chinese young students are generally positive and progressive, full of positive energy. They can persist in correct leadership of the CPC, and carefully learn and implement various lines and policies of the $\mathrm{CPC}$ and China in classroom learning and in spare time. Moreover, they also have a strong sense of responsibility for studying hard for great rejuvenation of Chinese nation. However, they are still involved in some issues that cannot be neglected. For instance, ideology generated on the level of foreign language classroom teaching is quite weak. Political appeal is too utilitarian. In terms of value, attention is only paid to short-term effect.

The third one is deficiency in management system. School teaching management departments will rank only by passing rate of TEM 4 and TEM 6. More seriously, they even link the passing rate of TEM 4 and TEM 6 together with the obtainment of degree certificate and graduation certificate. Some schools only require passing the exam regardless of other teaching contents. As a result, some students and teachers overlooked the essential meaning of English teaching. Some learners even took the obtainment of certificate as the purpose instead of emphasis on improvement to integrative competence of English. Thus, there is no time for them to consider how to cultivate students' core values through foreign language teaching. Nowadays, English teaching fails to comprehensively realize the purpose of cultivating students' autonomous learning ability. Moreover, foreign language teachers cannot effectively adopt the classroom teaching pattern with learners as subjects. Thus, foreign language teachers are making response to the pressure of TEM 4 and TEM 6. Consequently, it will be naturally neglected for education of learners' value system and for cultivation of individual comprehensive quality. 
Strategies for integrating cultivation of socialist core values into foreign language classroom teaching

Nowadays, foreign language textbooks are mainly of those ones formulated by this school. In this school, foreign language course teachers compile textbooks according to school running characteristics and major features of students. These textbooks involve wide subjects, and are closely correlated with the life of students. Moreover, these subjects are always issues with the attention of the whole society. They are ideological. At the same time, these subjects are featured by knowledge and authenticity. Main content of teaching contains environmental protection, ecology, traffic, energy and interpersonal relationship. Foreign language teachers should positively and reasonably integrate thought, patriotism, socialist ethics with Chinese characteristics and other contents into classroom teaching with foreign language knowledge as the carrier, letting the students really define their learning goals in foreign language learning, so as to cultivate a strong will to overcome various difficulties.

\section{Strive to realize perfect combination of knowledge with moral education with foreign language course standard as the basis}

Foreign language teachers should make an in-depth analysis on the important value of foreign language subject for sustainable development of students, carefully figure out moral connotation in foreign language textbooks in this school, and form comprehensive ideological and moral education standpoint with foreign language knowledge as the basis and instruction of various knowledge as the subject. In a school, relevant contents in Unit 1: My School are taught in a school at the beginning of the textbook, letting students understand a question: What is my major? Thus, we can help students to set up correct view of major.

\section{Create real environment, and let students experience effective combination of knowledge with moral education}

In classroom teaching design, foreign language teachers are responsible for information restricting in teaching design. Foreign language teachers should design classroom teaching with improvement to learning initiative, cognitive competence and instruction skill as the major purpose, make great efforts to allow students to integrate in practice for cooperative communication, and let students form positive emotion concepts, so as to promote them to improve their consciousness of positive participation in teaching activities.

\section{Promote integration of moral education in teaching by improving classroom teaching means}

Considering that foreign language subject is distinctively featured by communication and instrument, foreign language teachers should strive to deeply dig and properly apply moral education elements in foreign language textbooks according to education and teaching laws of this subject, and allow students to obtain sublimation of ideology and morality and soul baptism in foreign language classroom by integrating moral education into teaching. In the design of foreign language classroom teaching, foreign language teachers should comprehensively introduce education for core value system, so as to lead the students to form correct values, world outlook and outlook on life.

\section{Vigorously dig colorful moral education resources in foreign language textbooks}

Various traditional and modern teaching means should be utilized to become a qualified designer, organizer or leader in the design of foreign language classroom teaching. Only in this way, design of foreign language course teaching can be used to improve language competence of students, and forge their initiative and complete personality, so as to practice socialist core values in a better way, lead new prevailing customs of the present age, and give each student an opportunity to be outstanding in the future. On the one hand, improvement should be made to students' moral sense by in-depth study of relevant contents in foreign language textbooks, so as to help them to shape complete personality. Many stories, biographies and philosophic papers in foreign language textbooks are quite helpful for physical and psychological health of students. Foreign language teachers should introduce the 
method of value clarification into foreign language classroom discussion, select and determine values for students by teaching moral sense and values, and provide good contexts or opportunities for them. The theory of value clarification was developed from the 1960s. It advocates value relativism, and doesn't acknowledge shared values. It is easy to cause the thought view of individual centralism based on egoism. In all societies, there is a core value which leads at that time and integrates other values, such as socialist core values in the present society. Or, value system of the whole society will lose its foundation. Based on the understanding of insufficient resources of foreign language moral education, it is more necessary to apply reasonable views and teaching methods and start from the plasticity of value, so as to make it possible for educators of socialist core values to provide reasonable contexts and opportunities for section and determination of individual values.

\section{Adopt the comparative discussion teaching method of different values}

Foreign language teachers can attempt to simulate life opportunities of a western national leader and organize students to face the topic of dedication according to differences between values of western developed countries and socialist core values in teaching contents, make a comparative discussion on values of western countries and socialist core values with Chinese characteristics, and strive to draw a conclusion about whether this is a kind of work ethic, professional ethic, life value or life philosophical view. Students are involved in a heated discussion, expressing their opinions freely. Through intense discussion, students can reach a consensus as much as possible in foreign language classroom. To be specific, the spirit of utter devotion in values of western developed countries mainly emphasizes on embodiment of a higher-level meaning containing country, nation and society. On that account, above comparative discussion course teaching allows students to have deeper cognition of socialist core values.

\section{Conclusion}

To sum up, socialist core values are criteria of value and codes of conduct followed by numerous young students. Young students are the hope of socialism cause with Chinese characteristics. Their value appeal has great influence on development of Chinese society and inheritance of mainstream value guidance. Foreign language classroom teaching is an important approach for cultivation of core values of young students. Scientific and standard methods should be used to guide students to positively learn socialist core values in foreign language teaching. Such action can improve subjective initiative of students and teachers in learning and teaching of foreign language. Moreover, it can also improve students' consciousness and practical effect in accepting the education of core values.

\section{Acknowledgments}

This paper is a topic of annual research on development of social sciences in Hebei Province in 2015: Research on Cultivation of Socialist Core Values based on Foreign Language Classroom Teaching (No.: 2015020503).

\section{References}

[1] Sun Fucun, Teaching about How to Master Socialist Core Value System, Jiangsu Higher Education, 2008 (5);

[2] Fan Shucheng, Analysis on Core Value Education in America, Studies in Foreign Education, 2008 (7);

[3] Zhou Chunyan, Research on Effectiveness of Education for Undergraduate Socialist Core Value System, Journal of Soochow University (Philosophy \& Social Science Edition), 2009 (4);

[4] Luo Chunyan, Reflection on Integration of Socialist Core Value System into Middle School Education, Bridge of Century, 2012 (3); 
[5] Wang Yaowen, Establishment of Values of Vocational College Students Led by Socialist Core Value System, New Curriculum Research, 2011 (10) 